\title{
Retraction: Reproducible subcutaneous transplantation of cell sheets into recipient mice
}

Haruko Obokata, Masayuki Yamato, Satoshi Tsuneda \& Teruo Okano

Nat. Protoc. 6, 1053-1059 (2011); published online 30 June 2011; retracted 13 January 2016

Masayuki Yamato, Satoshi Tsuneda and Teruo Okano would like to retract this protocol after concerns were raised by the community about some of the figures. Specifically, concerns were raised that the fourth graph in Figure 5a and the first graph in Figure 5b look very similar, and some of the error bars look unevenly positioned. Masayuki Yamato, Satoshi Tsuneda and Teruo Okano have been unable to locate some of the raw data to verify these figures and are no longer confident in the paper's results. Given that these results are key to demonstrating the reliability and reproducibility of the protocol, these authors wish to retract the protocol, and they sincerely apologize for the adverse consequences that may have resulted from its publication. Haruko Obokata could not be reached by the journal for comment on the retraction.

\section{Corrigendum: Genome-wide copy number analysis of single cells}

Timour Baslan, Jude Kendall, Linda Rodgers, Hilary Cox, Mike Riggs, Asya Stepansky, Jennifer Troge, Kandasamy Ravi, Diane Esposito, B Lakshmi, Michael Wigler, Nicholas Navin \& James Hicks Nat. Protoc. 7, 1024-1041 (2012); published online 3 May 2012; corrected after print 24 February 2016

In the version of this article initially published, the units for the concentration of $\mathrm{NaCl}$ in the NST buffer described in the Reagent Setup section were incorrect. The correct unit should be mM. The error has been corrected in the HTML and PDF versions of the article.

\section{Erratum: Mapping Argonaute and conventional RNA-binding protein interactions with RNA at single-nucleotide resolution using HITS-CLIP and CIMS analysis}

Michael J Moore, Chaolin Zhang, Emily Conn Gantman, Aldo Mele, Jennifer C Darnell \& Robert B Darnell Nat. Protoc. 9, 263-293 (2014); published online 9 January 2014; corrected after print 24 February 2016

In the version of this article initially published, units were incorrectly reported in Step 2 of the Procedure. They have been changed from ' $\mathrm{mJ} \mathrm{cm}^{2 \prime}$ to ' $\mathrm{mJ}$ per $\mathrm{cm}^{2 \prime}$ in four instances. In addition, units that previously read ' $1=0.1 \mathrm{~J}$ per $\mathrm{m}^{2 \prime}$ have been changed to ' $1=1 \mathrm{~J}$ per $\mathrm{m}^{2}$. These errors have been corrected in the HTML and PDF versions of the article.

\section{Corrigendum: The PURE system for the cell-free synthesis of membrane proteins}

Yutetsu Kuruma \& Takuya Ueda

Nat. Protoc. 10, 1328-1344 (2015); published online 13 August 2015; corrected after print 6 January 2016

In the version of this article initially published, the units for concentration of the FD component listed in Table 1 are incorrect. The correct unit should be $\mu \mathrm{g} / \mathrm{ml}$. The spelling of the 'PUREflex' kit was also incorrect and has been changed to PUREfrex throughout. These errors have been corrected in the HTML and PDF versions of the article. 